\title{
THE EXPERIENCE OF WORK IN A CALL CENTRE ENVIRONMENT
}

\author{
SANET HAUPTFLEISCH \\ JS UYS \\ jsu@rau.ac.za \\ Department of Human Resource Management \\ University of Johannesburg
}

\begin{abstract}
This qualitative research study explored the work experience in a call centre environment in an information technology call centre based in South Africa, which service foreign customers exclusively. Three data collection methods were used, namely narratives, in-depth interviews with call centre consultants, and observation. Following a grounded theory approach, four themes were elicited, namely the perceptions of team members, uncertainty created by a constantly changing environment, perceived distances due to management practices, and depersonalisation experienced while actually dealing with customers. In addition to this, the reported impact of these themes on work performance was explored and compared to existing research.
\end{abstract}

Key words

Call centre, customer service industry, experience of work

Largely due to the technological development in the field of telecommunications, as well as the integration of telecommunications and information technology, the call centre industry has shown remarkable growth worldwide (Burgess \& Connell, 2004; Holman, 2003; Moller, Crous \& Schepers, 2004; Paulet, 2004; Russel, 2004). Especially since the 1990s, call centres have become the latest and clearest expression of efforts aimed at rationalising the provision of service through the use of communication and information technologies (Russel, 2004). This is commonly regarded as a direct result of organisations' attempts to provide customer service at a significantly lower cost (Paulet, 2004) in response to information and communication technology developments, business outsourcing practices, and internal reorganisation of enterprises (Burgess \& Connell, 2004).

Burgess and Connell (2004) contend that call centres are progressively becoming globalised operations and that call centre jobs are increasingly found outside the wealthy economies. In addition to this, these authors note a trend that is becoming more and more apparent, namely the relocation of call centres to countries with large pools of skilled and relatively cheap labour. As a consequence, a significant number of call centres are being relocated from Europe, North America and Australia to India, the Philippines and South Africa. According to Van Gass (2003), South Africa became attractive as a place to host call centres, particularly since the establishment of a second undersea fibre optic telephone link with Europe in February 2003. He further states that the world-class service levels of call centre staff in South Africa results in this country providing better opportunities than India.

However, as Fielding (2004) reports, call centres that began to emerge in the 80 s became victims of their own success by fuelling an increase in the quantity of customer demand for immediate better service. This resulted in working conditions not always being conducive to optimal consulting performance, and has lead to call centres being labelled as "sweat shops" of the nineties (Moller et al., 2004); "electronic sweatshops" (Healy \& Bramble, 2004; Holman, 2003; Russell, 2004; Wickham \& Collins, 2004); "dark satanic mills of the twenty first century" (Holman, 2003); "modern factories" (Bagnara, Gabrielli \& Marti, 2000); modern forms of Taylorism (Zapf, Isic, Bechtoldt \& Blau, 2003), and "white collar factories" (Wickham \& Collins, 2004).
To date, most call centre research focused on aspects such as causes of burnout, employee stress and well-being (Grandey, Dickter \& Sin, 2004; Grebner, Semmer, Faso, Gut, Kälin \& Elfering, 2003; Harris, Daniels \& Briner, 2003; Healy \& Bramble, 2003; Holman, 2003), as well as literature reviews on call centre research and trends from various perspectives (Bagnara et al., 2000; Burgess \& Connell, 2004; Mascia, Marx \& Arbix, 2000; Paulet, 2004; Read, 2005; Russell, 2004; Sznelwar Zilbovicius \& Soares, 2000; Wickham \& Collins, 2004; Workman \& Bommer, 2004; Zapf et al., 2003). Yet, the majority of studies are quantitative in nature, with a focus towards specific aspects in call centre settings compared to other work settings. This study aims to describe the general experience of work in a call centre environment, without emphasising a certain issue or stressor. The objective behind this approach is to determine aspects that are not necessarily stress related or negative in their environment but also potentially related to positive experiences.

For the purpose of this study, a call centre is defined as a place where as little as three telephones handle organisational issues (Rademeyer, in Moller et al., 2004). It is therefore a business that integrates advanced technology with an effectively designed business process and human resources. Taylor (in Paulet, 2004) suggests a number of aspects that differentiate call centres from other industries. These include the use of technology to control the nature of work, service activities that can be provided from any location, a geographically mobile industry, employees that have access to any information by the "touch of a button," and the substantial amount of control and surveillance over employees, resulting in distinctive work relationships and labour processes.

Healy and Bramble (2003) delineated call centres according to three criteria. Firstly, employees are in direct contact with clients, either through dealing with inbound calls, initiating outbound calls, or performing some combination of these roles. Secondly, call centres combine telecommunications and information systems technologies in a way that allows employees to interface with customers on the phone, while simultaneously entering information into a specialised computer programme. Finally, they facilitate managerial control over the labour process, through automatic call distribution (ACD) or predictive dialing systems, which distribute and set the pace of work, while simultaneously monitoring employee performance through real-time 
statistical displays. This creates an unprecedented degree of control, which is considered essential to the efficient functioning of the call centre.

Call centres therefore present an alternative contact point between the customer and the organisation by offering a onestop service without the high cost of one-to-one interaction (Moller et al. 2004). Therefore, a substantial amount of time is saved, as customers do not have to travel great distances to visit the organisation to address queries and problems. This then reflects the primary benefit of a call centre: its cost-effectiveness to the organisation, which explains the high growth rates of these centres referred to earlier.

However, despite the seeming cost-effectiveness of such call centres, this approach is not void of problems. Call centre managers are under constant pressure to meet the rapidly rising expectations, which they have to meet by making use of the most readily available model for organising large-scale work: mass-production (Fielding, 2004). Furthermore, although conventional wisdom maintains that mass production is the only way to operate, research is increasingly pointing out its damaging impact on both employees and customers (Bagnara et al., 2000; Fielding, 2004; Grandey et al., 2004; Grebner et al., 2003; Harris et al., 2003; Healy \& Bramble, 2003; Holman, 2003; Moller et al., 2004; Paulet, 2004; Sznelwar et al., 2000; Zapf et al., 2003).

In an overview of employee stress and well-being in call centres, Holman (2003) identified the following aspects as having strong positive effects on employee well-being: high control over work methods and procedures, and what is said to the customer; a sufficient degree of variety; a performance management system that is both aimed at the development of individuals and not perceived as being too rigid or severe; a supportive team leader, and supportive HR practices. If these aspects are not attended to, it can result in a variety of negative consequences, including increased absence and turnover rates; increased staffing, recruitment and training costs; decreased quality of customer service; increased errors; lower first-time call resolutions and more "unnecessary calls" (Holman, 2003). Ultimately, whereas the call centre should be more cost effective, lower employee well-being can in reality increase the total costs. Research by Workman and Bommer (2004) supported this conclusion in finding that negative attitudes due to damaging experiences in the call centre environment result in reduced productivity, poor customer service, higher turnover and absenteeism and ultimately, an adverse financial impact.

Bagnara et al. (2000) note that the integration of products and services has had a formidable impact on the actual human work in call centres. However, it appears that changes in technologies and activities often go unnoticed in the organisation of many call centres. People in call centres carry out complex activities, where unforeseeable problems are continuously experienced. Moreover, they are supposed to assist in mastering the relationship with the market, and possess knowledge about products, services, processes, clients. Nevertheless, they are often still being managed as industrial workers. Furthermore, organisations put the burden of high performance and smooth functioning on young people, who often possess rather high education but are offered lower positions and salaries. Thus, the resulting stress responses, high absenteeism, high turnover, and difficulties in personnel recruitment, management and retention are hardly surprising outcomes. As Kjellerup (in Bagnara et al., 2000) states, "Because of the heavy situations [call centres] are often a place [where] one works to make money to leave".

This research study aims to determine how call centre employees experience their general work environment by attempting to identify those factors that they experience as positive, as well as negative factors. Knowledge of both the positive and negative ways in which call centre employees experience their work environment, is potentially useful in reconsidering how the call centre is structured and operated, towards enhancing these aspects. It remains crucial that call centre employees be positive toward their jobs, as in many organisations, they form the main and only contact point with the customer. Subsequently, when these employees experience their work environment in a negative way, these feelings may consciously or unconsciously, be transferred to the customer, contributing to the adverse financial implications experienced by the organisation.

\section{RESEARCH DESIGN}

\section{Research approach}

The different ways of thinking about the research process involve different paradigms or worldviews, which, in turn, shape the research strategies to be used (Esterberg, 2002). The selection of the qualitative research approach can be summarised in the following quote from Leedy and Ormrod (2005, p.133):

To answer some of the research questions we cannot skim across the surface. We must dig deep to get a complete understanding of the phenomenon we are studying. In qualitative research, we do indeed dig deep: We collect numerous forms of data and examine them from various angles to construct a rich and meaningful picture of a complex, multifaceted situation.

According to Craffert (2001) a variety of aspects influence the choice of a particular research strategy, such as the researcher's epistemological framework, the objective of the study, the phenomenon under investigation and the researcher's training and skills. Guba and Lincoln (in Craffert, 2001) state that the researcher's epistemological stance is the determining factor in the choice of an approach and that the methodological or pragmatic issues take a secondary stance in this decision. This study, then, is situated within the interpretive paradigm, as the importance of the participants' life-world (context) and involvement in research are acknowledged.

Neuman (2000) defines the interpretative approach as the "systematic analysis of socially meaningful action through direct detailed observation of people in natural settings in order to arrive at understandings and interpretations of how people create and maintain their social worlds". The objective of this study therefore is to develop an understanding of the social life of the participants and to discover how people construct meaning in their natural settings, which in this study refers to the call centre environment.

An approach commonly applied in the interpretative paradigm and regarded as consistent with a contextual epistemology, is the grounded theory approach (Charmaz, 1995). This author further describes grounded theory methods as being used to discover the research participants' meanings, with the aim of capturing the worlds of the people by describing their situations, thoughts, feelings and actions, and by relying on portraying the research participants' lives and voices. Therefore, the participants' concerns will shape the direction and form of the research, as the researcher only seeks to learn how they construct their experience through their actions, intentions, beliefs and feelings. Furthermore, the role of the researcher can be described as an active, thinking co-participant in the process, not merely a mirror reflecting reality (Craffert, 2001). The study therefore proposes as one of its objectives the potential generation of theory, without a preconceived theory or hypotheses.

\section{Research Methodology}

Participants. Individuals were sampled based on their potential to contribute to the development of an understanding of the employee experiences in a call centre environment. The call 
centre of an IT organisation participated in the research. The call centre is based in South Africa, yet the customers they service are all based abroad. All call centre consultants are South African.

The call centre is divided into various teams, and permission was granted to involve one of the teams in the research. This team was comprised of 26 members, and consisted of $57 \%$ black, $12 \%$ coloured, $12 \%$ Indian, and 19\% white employees. Although, not all team members participated in the research study. The ten team members that participated in the study $(\mathrm{N}=$ 10) were aged between 21 and 29 years. All the participating team members had appropriate call centre experience in that particular environment, ranging from five months to approximately three years.

The researcher met with potential participants on one occasion to explain the nature and goals of the research study. As the most important criterion throughout the sampling process was the willingness to participate, potential participants were not pressurised to participate in the study. After the initial meeting, participants indicated via electronic mail whether they would be willing to participate. No motivation for their decision was requested.

Data collection technique. Three methods of data collection were used, namely a written narrative, an in-depth interview, and observations on two occasions. A narrative can be defined as "a kind of story told by someone" (Esterberg, 2002, p.182) with some kind of plot or action. The study required the participants to give a written narrative of their experience in the call centre environment, by answering the question: What do you experience as positive in your environment, and what can be changed to make it more positive (or to improve it)? This question was given to all 26 team members, of which 10 responses were received (38\% participation).

The qualitative interview can be applied to describe and interpret a particular theme or phenomenon in the life-world of a participant and the way they relate to it (Kvale, 1996), and was therefore decided upon as an appropriate and valid method of gathering data in this study. The researcher approached the ten participants that responded to the narrative regarding an interview, and seven participants agreed to participate (27\% participation). The information provided in each participant's written narrative, was used as background information to the interview.

To accommodate the participants' irregular working hours, it was left to them to determine the time and place for the interview. Interviews took a minimum of 45 minutes and a maximum of one and a half hours. No interviews were conducted at the workplace. Instead, three interviews were conducted in the participants' private home whilst the remainder took place in a public coffee shop. In each case, the interview was introduced by means of a re-explanation of the nature and objective of the study, a commitment to total confidentiality, and an opportunity for questions to address any further concerns regarding participation in the study. Permission was asked to audio-tape the interview so as to allow the interviewer the freedom to be attentive to the individual and participate in the process. All participants gave their consent.

The interviews were conversational in nature, and as with the narratives, participants were asked to give their opinions on the question: What do you experience as positive in your environment, and what can be changed to make it more positive, or to improve it?

The approach to the interviews was fairly flexible and participants shared their experiences in a way they felt comfortable. The interviewer interacted with the participants in the interview only by asking for clarification of or elaboration on specific comments. Furthermore, at certain points, the interviewer's understanding of the experiences or aspects in the environment was communicated to the participants in order to validate the correctness of the interviewer's perspective. This approach is in line with the interpretative paradigm, where the aim is to achieve an empathetic understanding of the feelings and world views of the participants, as people are seen as social beings who create meaning and who constantly make sense of their worlds (Neuman, 2000).

A third method used was observation. On two occasions, the researcher arranged for visits to the call centre at times in which the majority of the participants were on duty. Although the aim was to be as unobtrusive as possible, the physical lay-out of the call centre made this impossible at times. Nevertheless, care was taken not to interfere with the participants while they were working. The participants' general attitude and behaviours were observed, to enable the researcher to have a better understanding of how they would come across at work. Limited interaction occurred during their breaks but care was taken to avoid the topic of the study to avoid any influence on their natural behaviour.

\section{Data analysis}

The researcher, to allow for maximum familiarity with the data, transcribed all the interviews.

The grounded theory procedures followed in coding, analysing and interpreting data were based on Dey's (1993) approach.

(1) The coding process was started by selecting four diverse interviews and narratives from the group. Due to the high level of familiarity with the content of the narratives and interviews as result of the transcription process, that was done with relative ease.

(2) The process of reading and annotating followed, during which time themes were identified and comments made on experiences and any aspect that seemed noteworthy.

(3) A preliminary coding list with possible themes and categories was subsequently developed, whereafter similarities and differences in the narratives and interviews were identified.

(4) After the preliminary list was compiled, the remainder of the narratives and interviews were added to the initial four for reading and annotating.

(5) The preliminary coding list was then adjusted to include changes and additions resulting from the analysis of the rest of the narratives and interviews. Clarifying notes were added to the identified themes to clearly distinguish them from other categories, or to clarify some of the characteristics of the themes. This was done to ensure a conceptually clear and reliable coding process.

(6) At the end of this process, the code/theme list was relatively stable, with notes clarifying themes or criteria for selecting the particular theme.

(7) The coding/categorising process then followed. Here, actual data bits from each of the transcribed interviews and narratives are selected to specific themes on the basis of conveying a particular meaning.

(8) The transcribed interviews and narratives were then transformed, as each of the selected data bits were reorganised according to the themes. This assisted in gaining an impression of the relative dominance of a particular theme in the participants' experience.

(9) The individuals' experiences of the call centre environment were then described in a detailed discussion according to the identified themes. Field notes from the observations were also used for comparison.

(10) The data was then abstracted from the original individual context, and presented in the identified themes. This again gave an impression of the dominance of a particular theme and allowed for a better comprehension of the nature and complexity of an experienced theme.

(11) The data were then compared to existing literature on this topic, leading to both a conceptual and theoretical discussion of the experiences in a call centre environment. 


\section{Validity and Reliability}

Hammersley (in Denzin \& Lincoln, 1994) refers to the debate over what can be constituted as good interpretation in qualitative research. Denzin (in Craffert, 2001) states that in defining a study within the interpretive paradigm, a "value-free social science appears to be over," which necessitates the reinterpretation of the criteria for research in a value-laden context.

Reliability. Reliability refers to the absence of random errors, as these distort the object of the study (Smaling, 1992). In the present context, reliability does not refer to the verification of research findings through the replication of the study, but rather as involving the conscious revealing of the decisions and procedures followed in the various stages in the study (Craffert, 2001). As Dey (1993) states: by explaining the procedures followed in obtaining the results, the reader has the opportunity to scrutinise the procedure and decide in principle on the reliability.

Therefore, the procedures followed in the obtaining of the data, the transcription of the interviews and narratives, and the analysis and interpretation of the data are explained. Furthermore, participants' verbatim comments are provided as motivation for the decisions and interpretations.

Validity. The validity of a qualitative research study refers to the truthfulness of the results, and as "one which can be defended as sound because it is well-grounded conceptually and empirically" (Dey, 1993). The core meaning still involves the absence of random and systematic errors, as one can have reliability without validity, yet not validity without reliability.

One possible threat to the validity of a research study involves the researcher's own theories, preconceptions or values on the research process. As this will never be completely eliminated from any study, the researcher therefore regularly studied all notes and memoranda and analysed data without using special knowledge of the literature. In doing so, the researcher ultimately let the participants' experiences and feelings guide the research. The hallmark of grounded theory studies is that the researcher derives categories directly from the data, not from preconceived concepts or hypotheses (Charmaz, 1995), which could contribute to greater validity in the research study.

Triangulation. Reliability and validity can also be achieved with the aid of triangulation, where the object of research is studied in at least two ways (Smaling, 1992). This research used three methods of data collection, namely narratives, audio-taped interviews, and observation, thereby contributing to enhanced levels of validity and reliability.

\section{RESULTS}

The following four themes manifested in this research.

\section{Team members are seen as a support system}

The dominant positive aspect experienced in the work environment by call centre employees is the people [team members] they work with. From the responses it was determined that participants experience their team members as a source of motivation. Team members make work experiences enjoyable, whilst simultaneously acting as a source of knowledge, where the consultants learn form each other about work-related aspects as well as about life in general which help broaden their perspectives. "The people and the vibe and ... even though it's night shift ...you can't fall asleep with those people around", "... they bring across that positivity and it is them who motivate me to come to work ... they make it all worthwhile ...".

The call centre consultants perceive their fellow team members as a family structure of some sort. The primary motivation for this experience is the amount of time they spend together.
Subsequently, they all experience the same circumstances in the call centre and therefore a mutual understanding between the team members exist, where team members are seen as available and empathetic toward each other. In addition, consultants perceive their team as "... all on the same side ...", where team members will provide assistance to fellow team members if in a position to do so. "... they tend to become your family...because you spend so much time with these people at work, people fall in love with each other, they become best friends ... it's amazing, you start trusting them with your life ...", “... no matter who you are, race, skin colour, it doesn't matter ... we actually make a family ...". It also became apparent that if it were not for the people they work with, many of the participants would have left this work environment much sooner.

This family structure in the work environment further provides a support system to the call centre employees. One of the reasons is that the employees feel that they can vent their feelings to someone who has empathy and understanding of the experiences they go through. In addition, the call centre employees perceive their team members as reliable and always prepared to listen. “... it's like struggling together, suffering together ... that's why I say they're the people I enjoy working with the most, people that understand you, that know where you're coming from." "... no matter what anyone tells you at work, no matter how much anyone craps on you while you're at work, you can always offload all your problems to that person ... and they listen, it's there ... you miss it when it's gone ...".

It appears that, because of the closeness and support between the team members, they actually form quite a tight-knit unit, who will stand together in almost all situations. "... the teams ... if there's trouble, they will stick together, because they know that ... if you decide to be on your own that's going to be tough for you, because no one is going to give two hoots about you ... it somehow makes them stronger ...".

However, this tight-knit unit may have an adverse impact as well. It appears that, even though team members have positive effects on each other, negative feelings, attitudes and behaviours can also influence fellow team members. This could have possible damaging effects, as instead of motivating the team, it can also demotivate them "... when you have people around you that keep repeating the same negative things ... I end up despising some of them, 'cause they inflict that on me ...", "... I've noticed it ... if I'm called and I get irate and I start screaming, it affects the people around me in a negative way, because they sense that bad energy, which makes it [the work environment] really sour ...".

This positive experience surrounding fellow team members in a call centre environment has also been identified in research. Paulet (2004) reports a research study by Callaghan and Thompson that suggest that call centre employees often use communication and humour to address the frustration and irritation they experience. Healy and Bramble (2003) however, have a different opinion, as their research found that although the team provide call centre employees with a sense of membership, belonging and collegial support, the reality for most workers are quite different: at times work demands are so high that little time for interaction with fellow workers is available. However, these authors do state that call centre coworker support does appear to decrease the likelihood of emotional exhaustion and diminished personal accomplishment. This is also concluded by Grebner et al. (2003), who found that social stressors within the organisation, that is with colleagues and supervisors, is a powerful predictor of employee well-being.

\section{Constant changes in the environment lead to the} experience of uncertainty

The participants in the research study indicated constant changes in the work environment, which lead to a degree of uncertainty. This is accompanied by stressful experiences, as 
they continuously have to adapt to a constantly changing environment, resulting in perceptions of instability. "... you never really know what is expected of you, because it's always changing ... they change things too often ... one week it's formal wear, the next week they change it back ... it's depressing, you never know where you are, you don't feel stable ... it's change all the time ... this is in, that's out ... if there's just one set of rules, at least you can adapt to that ...".

These constant changes appear to impact the call centre employees in predominantly three main areas, which include the shifts they have to work, performance criteria which they are measured on, and service delivery.

Regarding shifts, the participants indicated a constantly changing system, which they have to adapt to with great difficulty. "... they change shifts where you work five days on and three days off, and shifts change every week ...". This is mainly due to the vastly different hours of the shifts, which they have to adapt to quite rapidly. The changes in shifts have two major impacts, the first being physical, and the second an impact on their personal lives.

The participants indicated that shift changes, especially regarding the hours they work, have great physical impacts. "... it's physical strain ... you can't work from 14:00 to 23:00, and then all of a sudden you're working from 23:00 to 07:00 ... it's hard for your body to adapt ... your eating patterns, your sleeping patterns, you lose weight ... you're miserable ...".

The weekly changes of shifts also have an impact on the consultants' personal lives and relationships. The hours during which they have to work are often very different from those of family members and partners, resulting in frustration and negativity. "... you work very bad hours, when you're lucky you get a 14:00 to 23:00 shift, which is the earliest shift they have ... yet the only time you see your family is when you have your day off, but if it's during the week, they're busy working ...". In addition, these irregular and uncomfortable hours also limit their social lives, which result in further negativity. "... we can never go out and you don't have a life and you get miserable ... I think to socialise is important, because then you're not miserable ...".

An important aspect to keep in mind when considering the impact shifts have on this call centre employees is their age. This could possibly explain the reported negative experiences, as the average age of the consultants range from early to mid-twenties, which is still fairly young. This age group indicate a mindset somewhat different than a person in his thirties, who generally has more responsibilities and commitments. "... if you take a look at the average age of the consultants, even the junior management, the average age of the entire call centre is 23 years...so they're still in the mindset of I want to go out and play, I want to go out and party, I want to enjoy my life ... so those shifts is very taxing on some of them ... they really take a lot out of people ...". Evidently, the hours the consultants have to work, does not allow them to do the [fun] things someone of their age would want to do. This is supported in the research by Healy and Bramble (2003), who note that younger employees appear to be more susceptible to emotional exhaustion, whereas older workers tend to be more depressed but more satisfied with the intrinsic aspects of their work.

A second area in which the change has a tremendous impact relates to the changing performance management criteria that call centre employees are measured against. These changes result in the call centre employees not being clear of managements' expectations, and cause insecurity. “... hey always say, these are the criteria ... then you meet them, and they go no, wait, we've got these criteria so you've got to change that and try to meet the second which is different from the first lot ... you never know what is expected of you, because it's always changing." The changing criteria, besides the uncertainty and insecurity, also cause high levels of stress, as it determines financial rewards and team composition. Insofar team composition is concerned, the level of team performance determines to which team the consultant is assigned. Yet, considering the importance of the relationships with fellow team members as discussed earlier, the possibility of changing teams could heighten stress levels more. “... every month teams are being done this ... every month we have a bigger team, every month it splits ... now the team is down to 8 people, where last month we had 40 people ...", "... we're more worried about the fact that teams are going to be split up ...".

Service delivery to customers is a third aspect affected by constant changes, especially when the changes implemented are not communicated to the call centre employees. In the present environment, it being an IT environment, existing products are constantly upgraded, improved or new products developed to enable them to keep up with market demands. However, the participants reported that these changes are often not communicated to them, resulting in embarrassment and loss of confidence when unable to assist customers due to lack of product knowledge. "... there's a lot of information coming in and they don't even let you know about it ... like, well, if they didn't tell me about it, how am I supposed to help the person ...?", "... it really eats away your confidence in your job when somebody calls in and they're like, I've got a problem with this...and you're like, what's that...and then you apologise and you go on ... and you don't really know anything about it ... it's really crappy...".

Sznelwar et al. (2000) note that one difficulty for the operator (call centre employees) relates to constant changes in the work, as new products are constantly introduced - sometimes without prior warning - yet there is no place or time for learning or incorporating new capabilities. Grebner et al. (2003) similarly describes instances where new products were widely advertised, yet call centre consultants were not informed in advance, resulting in them being confronted with customer questions that take them by surprise. This results in call centre employees having to read and memorise new information in approximately five minutes, prior to the beginning of the working day. Consequently, stress and negative experiences in the work environment, as well as lower levels of service delivery, inevitably ensues.

\section{Management practices that lead to perceived distances between management and consultants}

The participants also expressed concern over management practices, which are perceived as not always fair and supportive, and ultimately lead to a perception of management regarding them as replaceable. The call centre employees experience management as not treating staff properly, and without much consideration of or concern for difficulties faced. "... I feel we are not treasured and appreciated and we are made to feel we are replaceable ...".

The call centre employees' experiences about the way management handles the staff resulted in a perceived distance between themselves and management, where they do not always receive the support and guidance required. "... now in this environment, management looks after management, and consultants look after consultants...management is for themselves, once they get what they need, then that's cool ...".

One aspect strongly emphasised by the participants that could contribute to these perceptions are the general lack of recognition towards the consultants. "... it all comes down to recognition, a simple thank you and that ... you have no idea how much it mean ...". Participants reported numerous times when over-time work was performed, yet little or no recognition received. Even though some forms of recognition are given at times, this is not perceived as sufficient or consistent. "... in 
South Africa, the recognition, and recognition in the form of a job title, it means a lot more than giving me money ...".

As far as the support and guidance are concerned, the participants felt that management does not always deliver on their promises, and that there are occasions when management choose to turn their back on consultants rather than assist them when problems occur. This cause frustration and a sense of helplessness within the consultants, as the very person who is supposed to support and guide them, are often the most unsupportive. “... someone who's managing teams ... will come up to the team and say, you know ... I will break my back for you ... that's why I'm here as a team leader...next thing, that same person would turn around and say, it's not my baby ...". Yet, there are exceptions to the rule, and the managers and team leaders that gave them the support and guidance required, actually contributed to improved productivity and efficiency. “... if you've got somebody you know has your back ... its easier for you to work ...", "... one coach, he was great ... when we were with him we were performing ... we were the top team on the floor ... but it's not so anymore ...".

A further concern expressed by the participants refers to communication between management and the call centre employees. It appears that some management personnel are approachable whereas others not. This could further contribute to the negative experiences of call centre employees, as their source of support and guidance are either unapproachable, or uncommunicative. "... in terms of management, there are certain people you can talk to, and certain people you just stay away from ...".

However, these issues go further than communication between management and call centre employees to include other departments as well. As discussed earlier, new product information are not properly communicated to the call centre employees, and participants also reported frequent problems with salaries and payment, with unclear channels or procedures to get these problems resolved. There are no single person with whom payment issues can be discussed, resulting in consultants being sent back and forth between people, yet never receiving their full salaries. "... every month there's a payroll issue ... you never find one person where you can say okay, I worked this many hours, but my pay is short because of this and this ... now you have to fight people to pay you...g go to that one, go to that one, go to that one ... eventually you never get your money ...", This problem around payment is demotivating, as it affects the way call centre employees get by every day. "... some of the people that work here, aren't even from [this town], they work on a fixed budget ... rent money, and money that has to go to kids and who ever and whatever...the more they mess it up, the more that person's life get screwed over...".

Holman's (2003) research regarding the job and organisational factors contributing to employee burnout indicates that a supportive HR and leadership environment have positive effects on employee well-being. Therefore, as noted in the findings by Paulet (2004), the impact of HR and management (team leaders, coaches, and supervisors) cannot be underestimated, and it is important to determine whether a soft approach or a hard approach is followed. In a soft approach, the employees are treated more humanely, whereas a hard approach is characterised by employees being viewed as a resource, which can be replaced by new employees if burnout occurs.

The above-mentioned issues could provide a possible explanation to the high turnover rate in the company reported by the participants. "There's so many people that have left in the last year ... in one year they lost about $1400-1500$ people ...", "... and in that year and a half, they hired and trained close on 2500 people ... and in that department, they had only 470 people in total coming and going ... I mean if you look at 2500 compared to 400 , you're looking at $25 \%$ of all staff that came through the door and stayed ... $75 \%$ of that staff have come through, done their job, been good at it, and either moved on to better things, or couldn't handle it, and left ..." Not attending to the causes of employee well-being can also incur costs, as absence and turnover rates may increase, while the quality of customer service may decrease (Holman, 2003).

\section{Actually dealing with the customer causing a sense of depersonalisation}

Participants reported the call centre they work in as a challenging environment with a certain standard level that has to be met. One possible explanation to this reported challenging environment is that the call centre must compete against nine other call centres belonging to the same client, which already has nine years experience to their advantage, while this call centre has been involved for just over a year. The competition against the other call centres belonging to the same client therefore contributes to the emphasis on performance, which the participants experience as predominantly focused on the business and bottom-line results, rather than on individual growth and development. "... the pressure to actually get and maintain those standards is immense ..."

Actual customer interactions also place the call centre employees under a great amount of pressure, particularly since that particular customer that they are dealing with, are citizens of a foreign country, and not South African. The pressure is a result of the call centre employees having to adapt to the culture and ways of the customers, which lead to an experienced 'culture shock'. "... you go through an immense culture shock...little things like our jargon we use in everday life ... like 'ja', 'eish', 'howzit', you cannot use ... it's drummed into you ... you become immune to it ... you have to start speaking like [the foreigners], you have to start thinking in a [foreign] way ... it's an entire culture shock ...". A further difficulty facing the call centre consultants concern the South African political situation being brought up whenever the customer recognise the consultant as being South African. Consultants are not sure of the way in which to address such questions so that the customer is not offended in any way.

As in many call centres (Healy \& Bramble, 2003), the participants reported having a specific script that they have to follow, which also leads to experiences of stress, pressure and depersonalisation. These scripts force them to approach every call in the exact same manner, from opening the call through to the delivery of the resolution, while being constantly monitored by management. The participants further perceive the scripts as making them feel like "robots", due to the lack of sincerity and not allowing them to express their own personality. "... it becomes monotonous, it becomes stressful ... take a look at Chinese water torture, it's a constant drip ... you're constantly doing the same thing, day in and day out ... taking fifty, sixty calls per day ... it slowly drives you a little bit crazy ...". In addition, these scripts appears to create further difficulty when dealing with customers, "... because they give you these things that you have to say ... sometimes it's really hard to say because not all conversations are going in the very same way, and not all people are going to say exactly what you need them to say back ... but it's like ... you have to do this ...".

The repetitive, monotonous, intense and stressful nature of work in call centres also contribute to negative employee wellbeing (Healy \& Bramble, 2003). Holman (2003) suggests that the level of control that call centre employees have over the way they talk to their customers and how they do a work task are often regarded as more important than the level of control they have over their timing of work.

The pressure and stress experienced in dealing with the customers, as reported by the participants, appear to be, besides the difference in culture and restrictions imposed by scripts, a result of the fact that the call centre employees are also rated by 
the customers they have serviced. As reported, customers are sent a survey, where they have to rate the consultant on various aspects such as efficiency, politeness and product knowledge, which in turn impacts on their individual performance ratings. Therefore, some participants were of the opinion that obtaining good ratings by customers while simultaneously delivering quality service requires of them to compromise on some aspects at times, such as not following the script or adhering to the set call times. "... by the time they get to you, they're so worked up, you have to calm them down, to get them to understand where they are ... sometimes that person doesn't have a lot of time ... you've got to get all these points ... wasting their time ... you're not going to get very good stats, because you're wasting their time with things that they didn't even want or need ...".

Dealing with aggravated customers in a standardised, set manner also has an effect on the call centre employees. Being monitored and following the script while dealing with the customer, often lead to frustration. "... sometimes you get off a call or you'll be on a call and you'll put the phone on mute and throw your headset on the floor, because they're not listening to you, and they're not doing what you want them to do ...".

Healy and Bramble (2003) state that, in an effort to distance themselves from perceived sources of emotional strain, depersonalisation can emerge within the call centre employees. Furthermore, call centre employees are faced with the constant burden of meeting the customer's demands as quickly as possible, without compromising their performance in their managers' eyes. Holman's (2003) research also found that, if call centre employees have greater control over the emotions they display, dissonance between displayed and experienced emotions can be reduced, which can ultimately lead to improved employee well-being.

However, despite these issues, participants reported that they do regard the experience of service delivery as enjoyable, especially when it was of a satisfactory nature. “... sometimes you get off the phone, and it feels so good, it's really the best thing, being able to do what I'm supposed to do - I'm there to help people ...". This is also in line with Holman's (2003) finding that, even though the call centre environment itself can cause feelings of worry and anxiety, actively attending to and meeting a customer's needs, may also prove satisfying. As Healy and Bramble (2003) state, when customers are genuinely friendly and receptive, it bolsters the call centre employee's confidence, giving them the impression that their efforts are appreciated.

\section{CONCLUSION}

Following the results it appears that, within the South African customer service industry, a strong need for relationships exist. This is also applicable in the call centre environment, where participants' responses further emphasise the importance of people-relationships. However, circumstances within the environment do not always support this need. Management practices and attitudes toward the call centre consultants, including the perceived distances, lack of support and guidance, empty promises and unfair treatment consequently do not recognise this need for coherence and relationships.

In addition, the system within which the call centre employees operate also appears not to support this need for relationship building. Constant changes in the environment, resultant insecurity, high turnover and constant changes in team composition provide limited opportunity for relationship building. Furthermore, once-off interactions with customers and subsequent feelings of depersonalisation, do not provide much opportunity for the establishment of relationships.

It appears that, in order to fulfill this need, call centre employees form very tight and deep relationships with their team members, which possibly serve as an explanation for the highly positive experiences associated with team members. It is therefore important that organisations with call centres do not underestimate the importance of teams, and that more positive experiences be created by focusing interventions around teams and team-building.

In this particular call centre, four main themes were identified. Firstly, participants perceive team members as a support system. Secondly, the constant changes in the work environment lead to a high degree of uncertainty within the call centre employees. Thirdly, management practices result in perceived distance between the call centre employees and higher management levels. Finally, an experience of depersonalisation often occurs when call centre employees are dealing with the customer. These themes and impact thereof - as reported by the participants - were explored and analysed and then compared to existing relevant research.

The aim of this research study was to identify the experiences of employees in a call centre environment in order to identify the factors contributing to both positive and negative experiences which could ultimately assist in reducing the high rate of turnover and absenteeism in call centres in general. By identifying these factors, attempts were made to provide insights that will be valuable as guidelines in the design and structure of call centres in a manner that will reduce negative aspects and enhance positive ones towards ultimately increasing service delivered to customers. The value thereof is particularly evident in light of call centres rapidly becoming the only contact point between the customer and the organisation.

.A number of limitations and subsequent recommendations for further research have been identified in the context of this study. Firstly, the present research study was conducted within a single team in a particular call centre. Taking into account the high value the call centre employees attach to their team and fellow team members, the perceptions and experiences reported by the participants could be the result of a team identity that developed within the team, and not necessarily reflect the reality within the entire call centre. Further research should therefore aim to include more teams within the same call centre in order to establish whether the experiences between the different teams are similar.

A second limitation of this research study relates to the high turnover rate within the team that served as research participants. Although the turnover rate did prove meaningful in the experiences reported by the participants in this research, it is suggested that further research be aimed at drawing a larger sample, so that more accounts of experiences of work in a call centre environment can be compared.

This study was conducted in a call centre that firstly deals with highly advanced information technology products and secondly provides a service to foreign customers exclusively. Although these results can therefore not be generalised to all call centres either in South Africa or any other country, the results did prove meaningful for this study. It is recommended that further studies include more than one type of call centre, delivering different types of services, of which the customer base is not necessarily based in another country, as these results would prove useful for application in a South African context. Further research could also compare cultural differences between foreign cultures and indigenous customers.

\section{REFERENCES}

Bagnara, S., Gabrielli, F. \& Marti, P. (2000). Human work in call centres. Proceedings of the Human Factors and Ergonomics Society: Annual Meeting, 1, 553-556. Santa Monica.

Burgess, J. \& Connell, J. (2004). Emerging developments in call center research. Labour and Industry, 14 (3), 1-14. 
Charmaz, K. (1995). Grounded theory. In J.A. Smith, R. Harré \& L. van Langenhove (Eds). Rethinking methods in psychology. London: Sage.

Craffert, L. (2001). Understanding employees' experience of transformation in an academic institution. Unpublished doctoral dissertation, University of Pretoria.

Denzin, N.K. \& Lincoln, Y.S. (1994). Handbook of qualitative research. Thousand Oaks: Sage.

Dey, I. (1993). Qualitative data analysis. London: Routledge.

Esterberg, K.G. (2002). Qualitative methods in social research. Boston: McGraw-Hill.

Fielding, G. (2004, November). Understanding the need for change. Call Centre Focus (Online). Available: http://www.callcentre.co.uk/ccf/article.asp?id=646

Grandey, A.A., Dickter, D.N. \& Sin, H.P. (2004). The customer is not always right: Customer aggression and emotion regulation of service employees. Journal of Organizational Behavior, 25 (3), 397-409. Retrieved May 5, 2005 from the World Wide Web: http://0-proquest.umi.com.raulib.rau.ac.za

Grebner, S., Semmer, N.K., Faso, L.L., Gut, S., Kälin, W. \& Elfering, A. (2003). Working conditions, well-being, and jobrelated attitudes among call centre agents. European Journal of Work and Organizational Psychology, 12 (4), 341-365.

Harris, C., Daniels, K. \& Briner, R.B. (2003). A daily study of goals and affective well-being at work. Journal of Occupational and Organizational Psychology, 76 (3), 401-407. Retrieved May 5, 2005, from the World Wide Web: http://0proquest.umi.com.raulib.rau.ac.za

Healy, J. \& Bramble, T. (2003). Dial ' $b$ ' for burnout? The experience of job burnout in a telephone call centre. Labour and Industry, 14 (2), 39-60.

Holman, D. (2003). Phoning in sick? An overview of employee stress in call centres. Leadership and Organization Development Journal, 24 (3), 123-130.

Kvale, S. (1996). Interviews: An introduction to qualitative research interviewing. Thousand Oaks: Sage.

Leedy, P.D. \& Ormrod, J.E. (2005). Practical research: Planning and design ( $8^{\text {th }}$ ed.). Upper Saddle River, NJ: Pearson Prentice Hall.
Mascia, F.L., Marx, R. \& Arbix, G. (2000). Old paradigms for new jobs in call centers. Proceedings of the Human Factors and Ergonomics Society: Annual Meeting, 2, 543-546. Santa Monica: 2000.

Moller, Y., Crous, F. \& Schepers, J.M. (2004). 'n Ondersoek na die persoonlikheidseienskappe van inbelsentrumkonsultante. $S A$ Journal of Industrial Psychology, 30 (2), 74-84.

Neuman, W.L. (2000). Social research methods: Qualitative and quantitative methods. Boston: Allyn \& Bacon.

Paulet, R. (2004). Putting call centres in their place. Labour \& Industry, 14 (3), 77-90.

Read, B. (2005, May). Where call centers are going. Call Center Magazine, 18 (5), 58-59.

Russel, B. (2004). Are all call centres the same? Labour \& Industry, 14 (3), 91-110.

Smaling, A. (1992). Objectivity, reliability and validity. In G.J.N. Bruinsma \& M.A. Zwanenburg (Eds). Methodology for management specialists, pp.302-322. Muiderberg: Dick Coutinho.

Sznelwar, L.I., Zilbovicius, M. \& Soares, R.F.R. (2000). The structure of tasks at "call centers": Control and learning difficulties. Proceedings of the Human Factors and Ergonomics Society: Annual Meeting, 2, 547-550. Santa Monica: 2000

Van Gass, C. (2003, May 7). Call centre industry finds SA's pulse. Africa News Service (Online). Available: http://www.comtexnews.com

Wickham, J. \& Collins, G. (2004). The call centre: A nursery for new forms of work organisation? The Services Industry Journal, 24 (1), 1-18.

Workman, M. \& Bommer, W. (2004). Redesigning computer call center work: A longitudinal field experiment. Journal of Organizational Behavior, 25 (3), 317-330. Retrieved April 5, 2005, from the World Wide Web: http://0proquest.umi.com.raulib.rau.ac.za

Zapf, D., Isic, A., Bechtoldt, M. \& Blau, P. (2003). What is typical for call centre jobs? Job characteristics, and service interactions in different call centres. European Journal of Work and Organizational Psychology, 12 (4), 311-340. 